and Australia, all of them superior in area, and the two last, at least, of equal importance, commercially speaking, with the totality of the metricised nations. The Russian sagene is an exact multiple of the English foot (imperial). The hath (the legal measure of length in British India) is 18 imperial inches. The Australian system is identical with our own. Taking into consideration this immense preponderance, both in area, in population, and in commerce, we are not only justified in taking our stand against this innovation, but entitled to inquire, if uniformity be insisted on, why, with an equally good theoretical basis (to say the least), the majority is called upon to give way to the minority.

J. F. W. HerscheL.

Collingwoad, Jane 18.

For the Journal of the Franklin Institute.

\title{
Atmospheric Pressure as a Traveling Foree, versus Animal Power and Steam Locomotives.
}

(Continued from page 279 .)

It may readily be supposed that to establish Pneumatic passenger lines, the dimensions of the tunnels or tubes should be as small as possible, not only because their cost swells greatly with their bore, but because the larger one is the larger are the volumes of air to be drawn out, and the longer the time and greater the outlay of force to do that. This may be said to depend on the arrangement of the passengers seats. In common cars it matters little how they are placed, in the direction of the length or breadth of the cars, but in an air tube the difference is very great. Every addition to its width enlarges its capacity and cost. A company of soldiers can march in single file through a passage less than three feet wide, but not in squads of three or four abreast; so a pneumatic tunnel adapted for a single row of passengers can pass the same number through as a much larger one seated across it, and in the same time. If length be thus substituted for breadth, the result would be a tube, the cost of which would be reduced to a minimum, and, as it would seem, the expense of working it also.

What then is the form and size of such a tube? We assume that one whose section is a circle five feet in diameter could receive two rows of passengers seated vis $d$ vis as in fig. 1 , with the space under the seats excluded. The sitting posture would be uneasy for tall travelers and there would be a lack of head-room on going in and out. This would suggest the drawing in of the sides so as to form an ellipse by dividing of which vertically and taking half of it, we should have, with a slight modification, the second figure. But though here taken for a section of a tube of the smallest dimensions it can only be considered as that of the car, to which the tube proportionately enlarged would have to conform.

It is, however, obvious that so severe an economy of space and such a disposition of travelers would militate against, if they did not prove fatal to the system. The comforts and conveniences of travel would be materially lessened, social and confidential converse, except with 
adjoining individuals, would be out of the question, while almost every one would be cramped for want of room and change of position. Traveling in a single file cannot become a general feature of atmo-

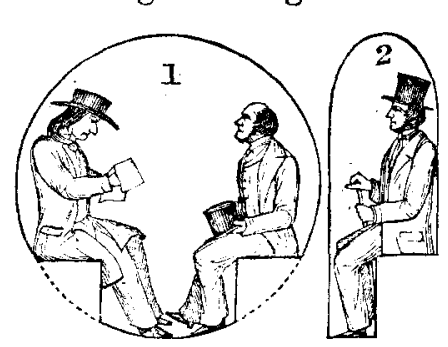
spheric lines, nor is it so essential in an economical point of view, as has just been supposed. The reasoning in the first paragraph is plausible and would be conclusive if a liquid instead of air had to be pumped out. It is to some extent superficial. Almost as much may be advanced in favor of the proposition that in the working of a line little is gained by a small tube over a large one.

Imagine two laid down of equal length, one having a sectional area twice that of the other, equal loads linked to the pistons, and each operated on by a like amount of exhausting power: would not the trains start together and reach the end of the routes at the same time, and with the same expenditure of force? While the larger one had a double quantity of air to remove, its density would only require to be half diminished. If the smaller piston had a pressure of $8 \mathrm{lbs}$. on the inch, that of the other would hare $4 \mathrm{lbs}$. on an area twice as large. So that, throwing friction of the pistons out of view, as regards speed and power, they would be much alike, and accommodations in common cars are compatible with Pneumatic tunnels of moderate dimensions.

The principle by which the resistance is accommodated to the force and the force to the resistance, is one of the fluid phases of the lever. Its applications may be supposed in their infancy, and this pumping of men and merchandise, like water, through pipes, a foreshadowing of its future operations.

E.

\section{Protecting Armor Plating. \\ From the London Artizan, Sept. 1864.}

Great success has attended the plan adopted for protecting the armor plating of the iron-cased wooden frigates, as applied in the first instance of the Royal Oak. This vessel has been admitted into the dock at Malta for the purpose of ascertaining the results of the measures adopted for preventing the effects of galvanic action on the armor plating. The plan, which was suggested by Mr. Reed, the chief constructor of the navy, consists in sheathing the plates with teak planking three inches in thickness, the inside of the planking and the surface of the armor plating being at the same time coated with Hay's water-proof glue, and the planking attached to the armor plates by short screws. Since the Royal Oak has been in dock at Malta a portion of the planking has been removed, and the results have been in the highest degree satisfactory, the armor plates having been perfectly protected, while not even the slightest trace of galvanic action can be detected. This improvement in the way of preserving the armor plating of wooden frigates is the more important when it is recollected 